Original Research Paper

\title{
Efficiency of EDTA and TWEEN 80 for the Removal of Chromium using Soil Washing Technologies
}

\author{
${ }^{1,2,3}$ Pantawat Sampanpanish and ${ }^{4}$ Nawaporn Thetthotsaporn \\ ${ }^{1}$ Environmental Research Institute, Chulalongkorn University (ERIC), Bangkok 10330, Thailand \\ ${ }^{2}$ Research Program of Toxic Substance Management in the Mining Industry, \\ Center of Excellence on Hazardous Substance Management (HSM), Bangkok 10330, Thailand \\ ${ }^{3}$ Research Unit of Green Mining Management (GMM), Chulalongkorn University, Bangkok 10330, Thailand \\ ${ }^{4}$ Interdisciplinary Program of Environmental Science \\ Graduate School, Chulalongkorn University, Bangkok 10330, Thailand
}

Article history
Received: 27-09-2017
Revised: 03-10-2017
Accepted: 18-01-2018
Corresponding Author:
Pantawat Sampanpanish
Environmental Research
Institute, Chulalongkorn
University (ERIC), Bangkok
10330, Thailand
Tel: 02218-8219
Fax: 02218-8210
Email: pantawat.s@chula.ac.th

\section{Introduction}

Contamination with heavy metals is a major problem that happens all over the world. Heavy metal contamination in soil can potentially lead to high environmental risks to human health and ecological security and it is necessary to remediate in such contaminated areas (Udovic and Lestan, 2008; Xuhui et al., 2015). Chromium (Cr) is one of the heavy metals most commonly found in the environment and normally highly absorbed in soil. Generally, it has been known that heavy metals are absorbed in soil with ion exchange and surface precipitation. In other words, it is sphere surface complexation and this is the term that has been widely used (Zhang et al., 2008).Chromium has two forms based on the principle of oxidation states including Hexavalent $\left(\mathrm{Cr}^{6+}\right)$ and Trivalent $\left(\mathrm{Cr}^{3+}\right)$; the quality of chromium depends on the molecular structure

\begin{abstract}
The study on the efficiency of chelate and surfactant for the removal of chromium using soil washing technology of which the chelate is EDTA and surfactant is TWEEN 80 at concentrations of 8, 16 and 32 soil with chromium contamination for 2 years. In this study, $20 \mathrm{~g}$ of TWEEN soil would be washed with 200 milliliters of EDTA and speeds of 90,120 and $150 \mathrm{rpm}$ for $15,30,60,90,120$ and $180 \mathrm{~min}$ and at every $3 \mathrm{~h}$ until it reached its equilibrium point at room temperature. After that it was filtered with filter paper before digestion with acid whereupon the obtained solution would be further analyzed. The study result revealed millimoles with $\mathrm{pH}$ of 10 and shaking speed of $120 \mathrm{rpm}$ and it could eliminate chromium at the level of $38.54 \%$. In the meantime, TWEEN 80 could remove chromium best at a concentration of 32 millimoles with $\mathrm{pH}$ of 10 and shaking speed of $150 \mathrm{rpm}$ and it could eliminate chromium at the level of $9.86 \%$. Therefore, when comparing efficiency between EDTA and removing chromium from soil than TWEEN 80.
\end{abstract}

Keywords: Soil Washing, Chromium, EDTA, TWEEN 80, Wastewater of the chromium composition, especially the oxidation state or oxidation number (Hawley et al., 2004).

Recently, technology of soil washing with proper extraction shows potential and is another alternative in treating and restoring contaminated soil (Maturi and Reddy, 2008; Dermont et al., 2008). Soil washing is a remediation process which is primarily used to treat soils and sludge which are contaminated with only one or two groups of contaminants (e.g., metals and/or volatile organic compounds) (Bilgin and Tulun, 2015). This process, however, has not been extensively employed on soils that are contaminated with pesticides in addition to metals and volatile organic compounds (Semer and Reddy, 1996). Soil washing is normally employed with different extracts such as acids, bases, chelating agents, electrolytes, oxidizing agents and surfactants (Zou et al., 2009). Chelating agents such as Ethylene Diaminetetraacetic Acid (EDTA) 
have the ability to capture heavy metals in stabilized form. More than that, they can be reformed to be soluble and movable in water. Therefore, EDTA is another substance that contributes to the removal of heavy metals from soil (Zhang and Lo, 2008; Sampanpanish and Pojanaporn, 2014). The washing method is utilized in restoring contaminated soil and it is acceptable when soils contain delicate soil content of less than $30 \%$. In fact, delicate soil content has size smaller than 0.075 millimeters, such as sands and silt or clayey sands mixed with organic and inorganic matter. However, for washing contaminated soil, it should have the composition of delicate content or muddy content. If the composition of delicate soil is more than $30 \%$, this method can be exercised but it also has limitations (Reddy and Supraja, 2000). For surfactants, it has been reported that this type of agent has good potential for removing metals in soil. However, popular surfactants are the cationic, anionic and nonionic types that can be used for washing (Mulligan et al., 1999) such as TWEEN 80, Triton X-100, Brij-35 (nonionic surfactant), SDS, AOT, SDBS (anionic surfactant) and hydrochloric acids (Kos and Lestan, 2004; Cheng et al., 2011; Xuhui et al., 2015; Min et al., 2017). According to the findings in many studies, filling surfactants in contaminated soil could enhance the emission and dissolution of contaminated organic matter because the solvent as cooled water needs to have a low Critical Micelle Concentration (CMC) related to a low value of toxic microbes (Cheng and Wong, 2006). Thus, this study was designed to show the efficiency of the chelating agent (EDTA) and surfactant (TWEEN 80) in removing chromium from contaminated soil using soil washing technology.

\section{Materials and Methods}

\section{Chemicals Preparation}

The chelating agent in this study is EDTA, purchased from Ajax (A.R. grade) and the nonionic surfactant is TWEEN 80 purchased from Rankem (Lab grade).

\section{Soil Preparation}

The soil in this study was chromium-contaminated soil through the study of plant toxicity and synthetic soil filled with potassium dichromate $\left(\mathrm{K}_{2} \mathrm{Cr}_{2} \mathrm{O}_{7}\right)$ with 2-year contamination. Basically, the soil property analysis included soil texture, $\mathrm{pH}$, Cation Exchange Capacity (CEC), Electrical Conductivity (EC), Organic Matter (OM) and Total Chromium (TCr).

\section{Experimental Design of Soil Washing}

Each set of experiments of soil washing would use $20 \mathrm{~g}$ of soil mixed with EDTA and/or TWEEN 80 as the solution for soil washing with concentrations of 8,16 and 32 millimoles and $\mathrm{pH}$ of 2, 4, 6, 8 and 10 adjusted with HCL or $\mathrm{NaOH}$. After that it would be mixed by shaking at speeds of 90, 120 and150 rpm for 15, 30, 60,
90, 120 and $180 \mathrm{~min}$ at every $3 \mathrm{~h}$ at ambient temperature until reaching the substance equilibrium. Finally, the clear part would be poured and filtered with filter paper for further analysis.

\section{Samples Analysis}

The concentration of chromium in the solution was analyzed with microwave digestion according to the principles of USEPA method 3051A (USEPA, 1998). After that, it was analyzed by Atomic Absorption Spectrophotometer (AAS).

\section{Statistical Analysis}

The statistical analysis was conducted through Analysis of Variance (ANOVA). In the case of different values, the comparison would be carried out with Duncan's New Multiple Range Test (DMRT) using the Statistical Package for the Social Sciences (SPSS) program.

\section{Results and Discussion}

\section{Physical and Chemical Properties of Contaminated Soil}

In this experiment the researcher used soil contaminated with synthetic chromium for 2 years which had been used for experiments with plants as a toxicity indicator. The results of the physical and chemical analysis of soils (Table 1) revealed that the soil was silty clay with a ratio of sand: Silt: Clay at 65.20: 9.20: 28.60. Soil with large amounts of sand could be well washed (USEPA, 1993). The soil $\mathrm{pH}$ was 3.57 which was deemed to be extremely acidic (FES, 2005). For ion exchange, the cation was 3.3 centimole/kilogram $\left(\mathrm{cmol}_{(\mathrm{c})} \mathrm{kg}^{-1}\right)$ and conductivity was 0.37 decisemen $/$ meter $(\mathrm{dS} / \mathrm{m})$ while organic matter in the soil accounted for $0.6 \%$ which was regarded as soil with organic matter as normal, since good soil should contain more than $1.5 \%$ organic matter (Yongyut, 2000). Concentration of all chromium in the soil was 466.4 milligram/kilogram which considerably exceeded soil quality standards for residential and agricultural purposes.

Table1: Physical and chemical properties of soil

\begin{tabular}{lc}
\hline Soil properties & Values measured \\
\hline Sand (\%) & 65.20 \\
Silt (\%) & 9.20 \\
Clay (\%) & 28.60 \\
Soil texture & Sandy clay loam \\
Soil pH & 3.57 \\
Nitrogen $(\%)$ & 0.03 \\
Phosphorus $(\mathrm{mg} / \mathrm{kg})$ & 8.00 \\
Potassium $(\mathrm{mg} / \mathrm{kg})$ & 564.00 \\
Cation exchange capacity $\left(\mathrm{cmol}(\mathrm{c}) \mathrm{kg}^{-1}\right)$ & 3.30 \\
Electrical conductivity $\left(\mathrm{dS} / \mathrm{m}^{-1}\right)$ & 0.37 \\
Organic matter $(\%)$ & 0.60 \\
Total chromium $(\mathrm{mg} / \mathrm{kg})$ & 466.40 \\
\hline
\end{tabular}




\section{Removal of Chromium with EDTA}

The experimental result on the efficiency of chromium-contaminated soil washing showed that the proper time for soil washing or the time of equilibrium was $30 \mathrm{~min}$. Therefore, reporting the findings would take into account only these times. Nevertheless, the results on studying the chelating agent EDTA indicated that a concentration of 8 millimoles and $\mathrm{pH}$ of 10 provided the best condition for soil washing which was statistically significantly different from $\mathrm{pH}$ at $2,4,6$ and $8(\mathrm{p} \leq 0.05)$ at shaking speeds of 90 and $150 \mathrm{rpm}$ with the percentages of chromium removal at 12.77 and $26.84 \%$, or $59.56 \pm 0.45$ and $125.18 \pm 0.66$ milligram/kilogram, respectively. This result also confirmed the findings of Zou et al. (2009) who reported that consecutive extractions using low concentrations were more effective than a single extraction with concentrated EDTA if the same dose of EDTA was used. Meanwhile, at a shaking speed of 120 rpm and $\mathrm{pH}$ of 6 , the percentage of chromium removal was $17.91 \%$ as shown in Fig. 1a while at a concentration of EDTA at 16 millimoles, the findings revealed that at every shaking speed with $\mathrm{pH} 10$, soil could be best washed, which was significantly distinct from other $\mathrm{pH}$ values $(\mathrm{p} \leq 0.05)$ and the percentages of chromium removal were $16.93,26.76$ and $35.57 \%$ or $78.96 \pm 0.54$, $124.81 \pm 0.98$ and $165.9 \pm 0.85$ milligram/kilogram, respectively, from high to low shaking speeds as shown in Fig. 1b. In addition, at an EDTA concentration of 32 millimoles, the findings indicated that at every shaking speed with $\mathrm{pH} 10$, the soil could be washed best and it was statistically significantly different from other $\mathrm{pH}$ values $(p \leq 0.05)$. At shaking speeds of 90,120 and $150 \mathrm{rpm}$, the percentages of chromium removal were $17.71,38.5 \%$ and $35.8 \%$ or $82.6 \pm 0.43,179.75 \pm 0.37$ and $166.97 \pm 0.59$ milligram/kilogram as shown in Fig. 1c (Dave et al., 2011). Normally, solutions in acid condition can leach heavy metals better and more effectively than those in alkalinity. Chromium-contaminated soil washing with EDTA solution will result in reaction of chromium complex compounds $\left(\mathrm{C}_{10} \mathrm{H}_{13} \mathrm{CrN}_{2} \mathrm{O}_{8}\right)$ affecting chromium solubility. Nevertheless, when adjusted to be in acidity, the chromium complex compounds $\left(\mathrm{C}_{10} \mathrm{H}_{13} \mathrm{CrN}_{2} \mathrm{O}_{8}\right)$ will turn to be $\mathrm{Cr}(\mathrm{OH})_{3}$ with decreased solubility. In the meantime, when $\mathrm{pH}$ is increased or in alkalinity, the chromium complex compounds $\left(\mathrm{C}_{10} \mathrm{H}_{13} \mathrm{CrN}_{2} \mathrm{O}_{8}\right)$ will turn to be $\mathrm{CrO}_{4}{ }^{2-}$ with increasing solubility (Bibhabasu and Amit, 2011; Kawalpreet and Michelle, 2014). Furthermore, according to the outcome of the soil washing experiment with EDTA, the efficiency in removing chromium was at an improper or ineffective level because chromium has the anion structure as shown in Equation 1:

$$
2 \mathrm{CrO}_{4}{ }^{2-}+2 \mathrm{H}^{+} \leftrightarrow 2 \mathrm{HCrO}_{4}^{-} \leftrightarrow \mathrm{Cr}_{2} \mathrm{O}_{7}^{2-}+\mathrm{H}_{2} \mathrm{O}
$$

However, while chromium solution could be in EDTA in anion form, it could not be captured with the structure of EDTA; thus, this experiment was consistent with Pichtel and Pichtel (2009) who measured chelating agents of EDTA and NTA and the anion surfactant of SDS. They found that EDTA was more efficient than NTA in eliminating lead and chromium. In addition, efficiency would be enhanced when the concentration of the chelating agents increased; at 0.1 mol concentration of EDTA, it could remove lead and chromium accounting for 96.2 and $84 \%$ respectively at $\mathrm{pH} 12$. In the meantime, SDS could remove lead and chromium at 30-40.5 and 29.35\% respectively (Salehian et al., 2012). Additionally, the findings correspond to those of Lim et al. (2004) who examined the use of nitric acid and the chelating agent EDTA in washing heavy metals contaminating soil; EDTA was a composition that had efficiency in removing lead and cadmium in soil with a high $\mathrm{pH}$ exceeding that of nitric acid. The findings also proved that only $15 \mathrm{~min}$ of shaking time could remove heavy metals contaminating soil. Hence, removing chromium with a chelating agent may have low efficiency and the concentration of the chelating agent may be increased for more effective chromium removal. This result also corresponds to that of Sun et al. (2001) who suggest that the lability of metals in soil, the kinetics of metal desorption/dissolution and the mode of EDTA addition were the main factors controlling the behavior of metal leaching with EDTA.

\section{Removal of Chromium with TWEEN 80}

According to the experiment on the efficiency of chromium contaminated soil washing at $30 \mathrm{~min}$, which was the substance equilibrium point with the surfactant TWEEN 80 at 8 millimoles concentration at its lowest, a shaking speed at 120 and $150 \mathrm{rpm}$ and $\mathrm{pH}$ of 10 was the condition which removed chromium with the highest efficiency and this was different from other $\mathrm{pH}$ values with statistical significance $(p \leq 0.05)$ as shown in Fig. 2a. The result was similar to that of Oudghiri et al. (2015) who used the chelating agent to remediate the sediment. The result promoted the notion that the addition of EDTA with pH 8 causes more positive outcomes than $\mathrm{pH} 3.8$. The percentages of chromium removal were 3.48 and $9.67 \%$ or $16.23+0.61$ and $45.1+0.34$ milligram/kilogram, respectively. However, chromium was mostly eliminated at a shaking speed of $90 \mathrm{rpm}, \mathrm{pH} 2$, accounting for $5.91 \%$ or $27.56 \pm 0.83$ milligram/kilogram. Meanwhile, at 16 millimoles concentration, 90, 120 and $150 \mathrm{rpm}$ shaking speed and $\mathrm{pH} 10$ of TWEEN 80, soil could be best washed which was statistically significantly different from other $\mathrm{pH}$ values $(\mathrm{p} \leq 0.05)$ with chromium removal percentages of 5.98, 4.31 and $9.79 \%$ or $27.89 \pm 0.96,20.10 \pm 0.94$ and $45.66 \pm 0.43$ milligram/kilogram, respectively (Fig. 2b). 


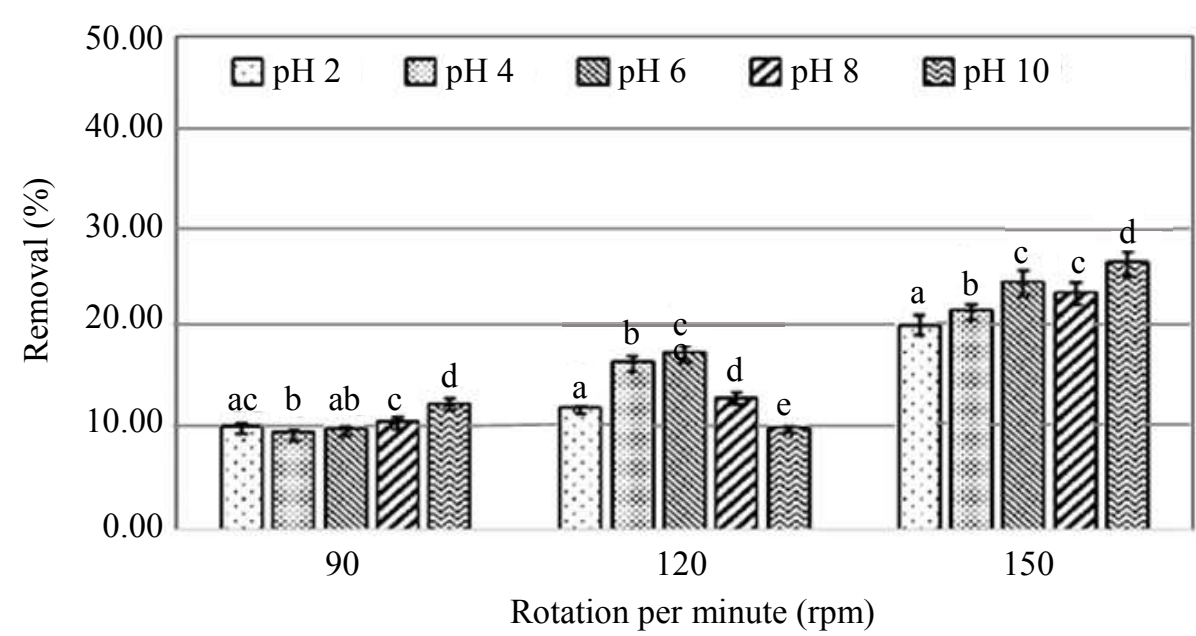

(a)

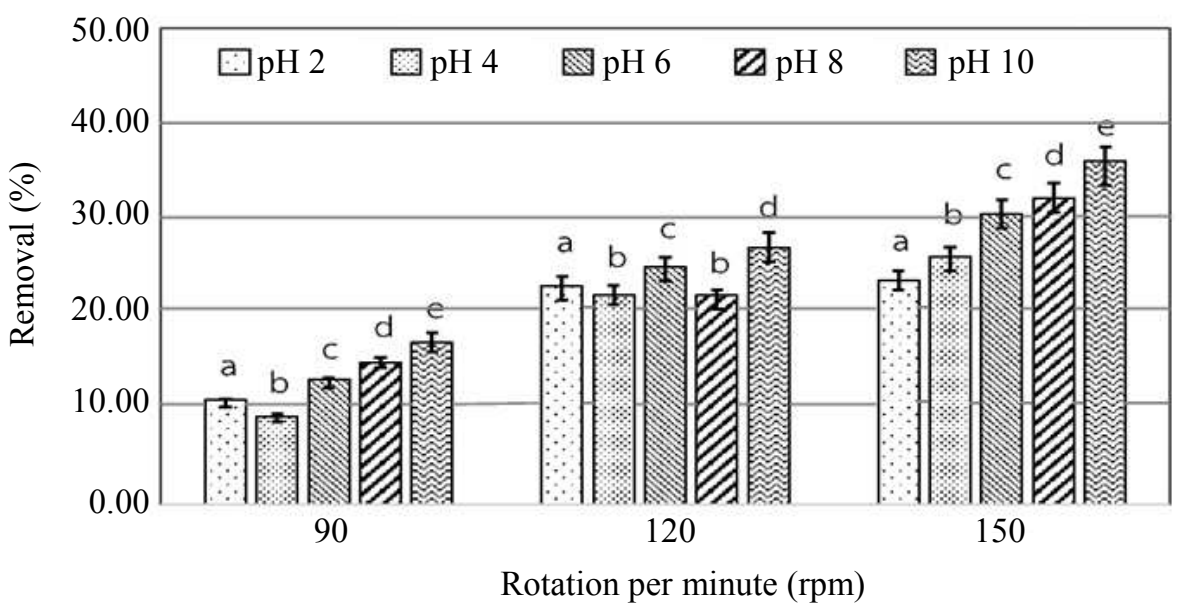

(b)

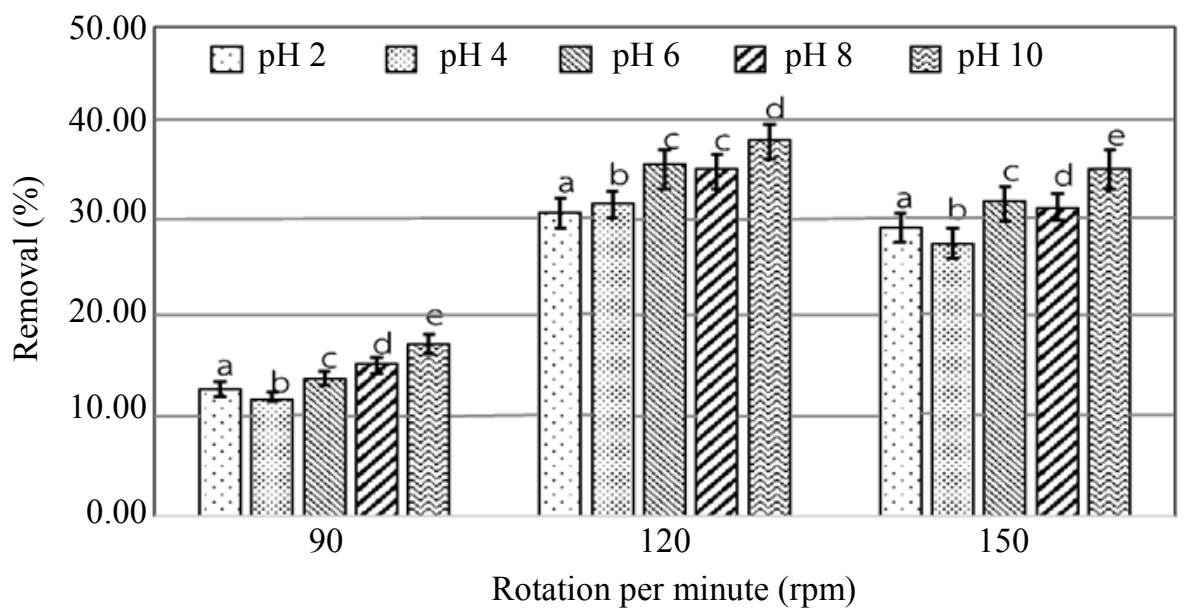

(c)

Fig. 1: Removal of chromium using EDTA at a concentration level, (a) $8 \mathrm{mM}$ (b) $16 \mathrm{mM}$ and (c) $32 \mathrm{mM}$; Note: The different English characters represent the statistical difference 95 percent confidence interval between different sets of the experiments using One Way ANOVA and to compare the difference in data using Duncan's new Multiple Range Test (DMRT) 


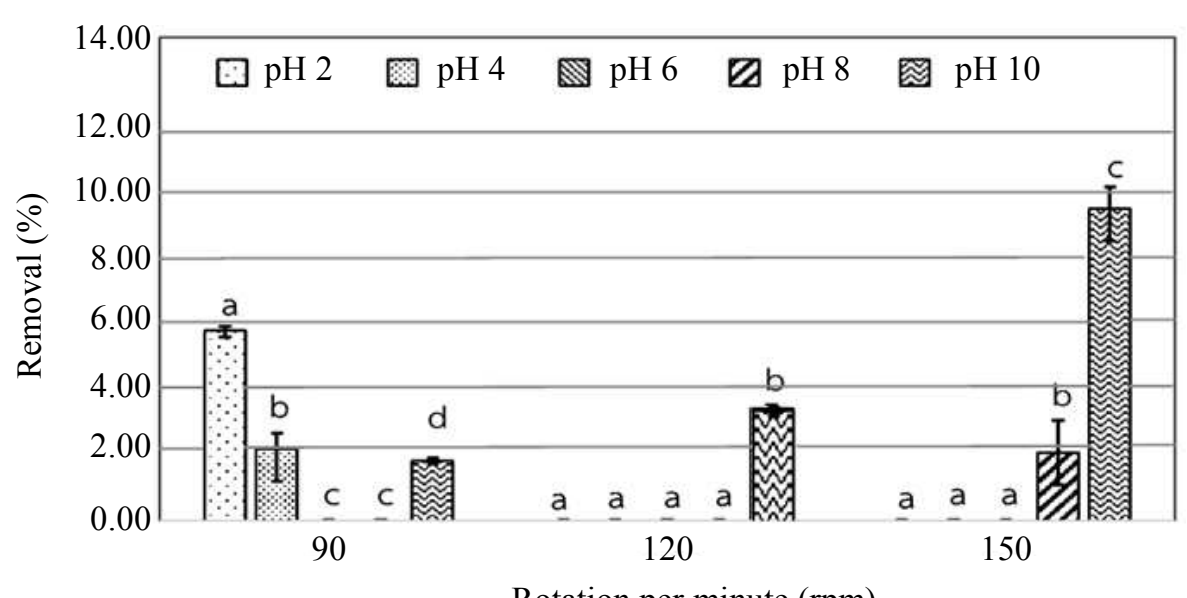

Rotation per minute (rpm)

(a)

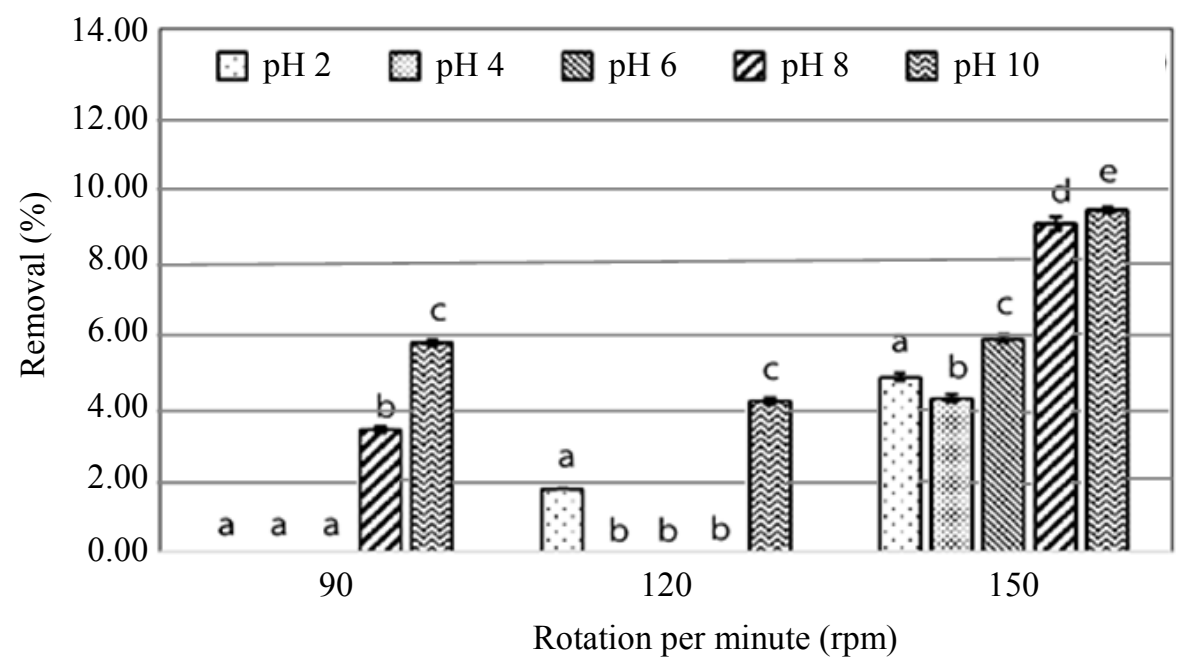

(b)

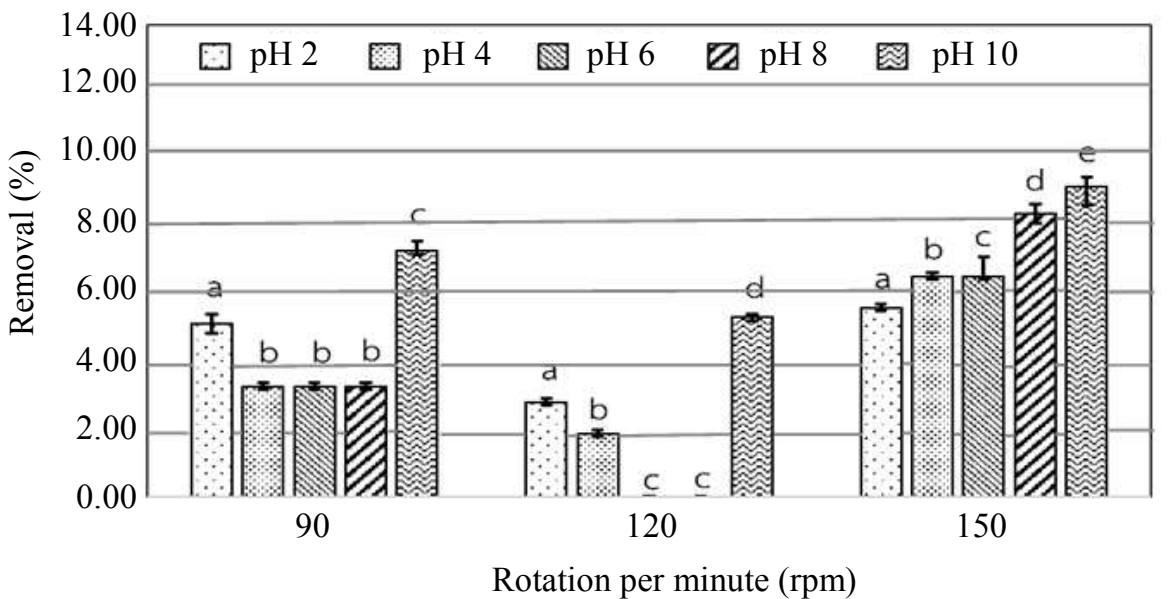

(c)

Fig. 2: Removal of chromium using TWEEN 80 at a concentration level, (a) $8 \mathrm{mM}$ (b) $16 \mathrm{mM}$ and (c) $32 \mathrm{mM}$; Note: The different English characters represent the statistical difference 95 percent confidence interval between different sets of the experiments using One Way ANOVA and to compare the difference in data using Duncan's new 
Moreover, at 32 millimoles concentration of TWEEN 80, which was the highest concentration, the findings indicated that at shaking speeds of 90, 120 and $150 \mathrm{rpm}$ and $\mathrm{pH} 10$, soil could be best washed which was statistically significantly different from other $\mathrm{pH}$ values $(\mathrm{p} \leq 0.05)$ with chromium removal percentages of $7.79,5.69$ and $9.86 \%$ or $36.33 \pm 0.53, \quad 26.54 \pm 0.98$ and $45.98 \pm 0.19$ milligram/kilogram (Fig. 2c). Furthermore, this study also discovered that the efficiency of chromium removal with TWEEN 80 was substantially lower due to the surfactant which reduced the surface tension in the form of an electric charge (Xuhui et al., 2015). When dissolved in water, cations would be decomposed resulting in the chromium being impossible to remove because of this reason. This aligned with Villa et al. (2010) who reported the use of TX-100 surfactant which is a nonionic agent which, when changing concentration of TX-100 from 3 to $12 \mathrm{cmc}$, could remove chromium from 0.12 to 0.14 milligram/liter and was not statistically significantly different. Tween 80 is a nonionic surfactant. According to the study of Bloor et al. (2006) examining effect of acidity-alkalinity on quality of Nonionic Surfactant Micellar, the findings revealed that the increase of $\mathrm{pH}$ in alkalinity possibly affects size of Nonionic Surfactant Micellar and it is likely to become smaller when being in high alkalinity. In addition, Neelam and Mamta (2008) performed an experiment and discovered that size of Micellar influenced aqueous solubility provided that minute Micellar will be more efficient in solubility than larger ones. Nevertheless, it is because small Micella contains more surfaces than bigger Micellar. The findings conformed to this study that high $\mathrm{pH}$ or alkalinity enhances efficiency of soil washing.

\section{Comparison of Efficiency for the Removal of Chromium between EDTA and TWEEN 80}

Comparing EDTA and TWEEN 80 at every concentration, at shaking speeds of 90,120 and $150 \mathrm{rpm}$, the researcher found that EDTA could remove chromium at every $\mathrm{pH}$ value because EDTA could be combusted with heavy metals in a wide range of $\mathrm{pH}$ values. It could eliminate chromium best at $\mathrm{pH} 10$ accounting for $38.54 \%$ at 32 millimoles concentration of EDTA and shaking speed of $120 \mathrm{rpm}$. In the meantime, TWEEN 80 could remove chromium best at $\mathrm{pH} 10$. For other $\mathrm{pH}$ Values, it could eliminate little or no chromium; moreover, TWEEN 80 could remove chromium at most at only $9.86 \%$ at 32 millimoles concentration and shaking speed of $150 \mathrm{rpm}$. According to the findings, chromium removal with EDTA and TWEEN 80 had low efficiency; however, EDTA could eliminate chromium 33.91 times or $20 \%$ more than TWEEN 80. Thus, comparing efficiency between EDTA and TWEEN 80, the researcher would say that EDTA could remove chromium better than TWEEN 80; in other words, TWEEN 80 was not powerful enough in eliminating chromium with the washing method. This finding concurred with Khalil et al. (2015) who found the capability of EDTA in the removal of copper to be better than SDS. Moreover, Luis et al. (2012) found that soil washing to remove arsenic and zinc using TWEEN 80 could remove 42.6 and $85.4 \%$, respectively. These results were similar to the reports of Metka and Domen (2009) and Abumaizar and Smith (1999), who stated that EDTA addition can cause positive effects in terms of heavy metal removal with the soil washing process. The results were similar to those of Gitipour et al. (2011) who studied the effects of soil washing on the removal of chromium and cadmium contaminated sludge from oil refinery ponds. The sediment samples were collected from various sources in the pond and the sediment was washed with EDTA and hydrochloric acid. The results showed that the addition of $0.3 \mathrm{MHCl}$ and EDTA $0.1 \mathrm{M}$ have a positive effect on chromium and cadmium removal from soil, reaching levels of more than $70 \%$.

\section{Conclusion}

This study concluded that the chelating agent EDTA could be used for soil washing with more efficiency in chromium removal than the surfactant TWEEN 80, which barely eliminated chromium. The best concentration for EDTA and TWEEN 80 was 32 millimoles and the best $\mathrm{pH}$ value was 10 . Shaking speed slightly affected soil washing compared with concentration and $\mathrm{pH}$ at the same level. Nevertheless, since Chromium has different valences, such as Chromium trivalent $\left(\mathrm{Cr}^{3+}\right)$ and Chromium hexavalent $\left(\mathrm{Cr}^{6+}\right)$ which could have oxidized or reduced in natural conditions, EDTA had low efficiency in removing chromium and TWEEN 8 had no efficiency in eliminating chromium. However, to enhance the efficiency of chromium removal with the washing method there should be further studies on other types of chelating agents and surfactants with cation, anion, or no charge and studies on washing soil contaminated with different heavy metals or the use of both substances in simultaneous or alternating ways which may provide the enhancement of heavy metal removal using soil washing methods. Furthermore, future studies should investigate functional groups of chromium by employing FourierTransform Infrared Spectroscopy (FTIR) in order to explain mechanism of reaction or bonding between chromium with complex compounds and soil surfactants.

\section{Acknowledgement}

The authors thank the Office of Higher Education Commission (OHEC) and the S\&T Postgraduate Education and Research Development Office (PERDO) for the financial support of the Research Program and thanks the Ratchadaphisek Somphot Endowment Fund, 
Chulalongkorn University for the Research Unit. We would like to express our sincere thanks to the Environmental Research Institute (ERIC) and the Center of Excellence on Hazardous Substance Management (HSM), Chulalongkorn University, for their invaluable supports in terms of facilities and scientific equipment.

\section{Author's Contributions}

This article is original research paper. Authors participated in all experiments, coordinated the dataanalysis and contributed to the written and read of this manuscript. Authors give final approval of the version to be submitted this journal.

\section{Ethics}

The authors declare no conflicts of interest and confirm that the manuscript has been submitted solely to this journal and is not published, in press, or submitted elsewhere.

\section{References}

Abumaizar, R.J. and E.H. Smith, 1999. Heavy metal contaminants removal by soil washing. J. Hazardous Mater., B70: 71-86.

DOI: $10.1016 / \mathrm{S} 0304-3894(99) 00149-1$

Bibhabasu, M. and B.M. Amit, 2011. Removal of heavy metal by screening followed by soil washing from contaminated soil. Int. J. Technol. Eng. Syst., 2: 291-293.

Bilgin, M. and S. Tulun, 2015. Removal of heavy metals $(\mathrm{Cu}, \mathrm{Cd}$ AND $\mathrm{Zn})$ from Contaminated soils using EDTA and $\mathrm{FeCl}_{3}$. Global Nest J., 18: 98-107.

Bloor, J.R., J.C. Morrison and C.T. Rhodest, 2006. Effect of $\mathrm{pH}$ on the micellar properties of a nonionic surfactant. J. Pharmaceutical Sci., 59: 387-390. DOI: $10.1002 / j p s .2600590325$

Cheng, K.Y. and J.W.C. Wong, 2006. Combined effect of nonionic surfactant TWEEN 80 and DOM on the behaviors of PAHs in soil-water system. Chemosphere, 62: 1907-1916.

DOI: $10.1016 /$ j.chemosphere.2005.07.028

Cheng, S.F., C.Y. Huang and Y.T. Tu, 2011. Remediation of soils contaminated with chromiumusing citric and hydrochloric acids: The role of chromium fractionation in chromium leaching. Environ. Technol., 32: 879-889. DOI: $10.1080 / 09593330.2010 .517218$

Dave, D., R. Alharathi and Ghaly, 2011. Sequential remediation processes for effective removal of oil from contaminated soils. Am. J. Environ. Sci., 7: 477-491. DOI: 10.3844/ajessp.2011.477.491

Dermont, G., M. Bergeron, G. Mercier and R.M. Lafleche, 2008. Soil washing for metal removal: A review of physical/chemical technologies and field applications. J. Hazardous Mater., 152: 1-31. DOI:10.1016/j.jhazmat.2007.10.043
FES, 2005. Basic of Geology. 10th Edn., Faculty of Earth Science, Kasetsart University, Bangkok.

Gitipour, S., S. Ahmadi, E. Madadian and M. Ardestani, 2011. Soil washing of chromium- and cadmiumcontaminated sludge using acids and ethylenediaminetetra acetic acid chelating agent. Environ. Technol., 37: 145-151. DOI: $10.1080 / 09593330.2011 .597784$

Hawley, E.L., R.A. Deeb, M.C. Kavanaugh and J.R.G. James, 2004. Treatment Technologies for Chromium (VI). In: Chromium(VI) Handbook, Guertin, J., J.A. Jacobs and C.P. Avakian (Eds.), CRC Press LLC, ISBN-10: 0203487966,pp: 275-309.

Neelam, S. and K. Mamta, 2008. Micellar solubilization of some poorly soluble antidiabetic drugs: A technical note. AAPS Pharm. Sci. Tech., 9: 431-436. DOI: $10.1208 / \mathrm{s} 12249-008-9057-5$

Kawalpreet and Michelle, 2014. Release of chromium from soils with persulfate chemical oxidation. Groundwater, 52:748-755. DOI: $10.1111 /$ gwat.12116/full

Khalil, A.H., S.S. Alquzweeni and H.M. Modhloom, 2015. Removal of copper ionsfrom contaminated soil by enhanced soil washing. Int. J. Environ. Res., 9: 1141-1146. DOI: 10.22059/ijer.2015.1003

Kos, B. and D. Lestan, 2004. Chelator induced phytoextraction and in situ soil washing of $\mathrm{Cu}$. Environ. Pollut., 132: 333-339. DOI: 10.1016/j.envpol.2004.04.004

Lim, T.T., J.H. Tay and J.Y. Wang, 2004. Chelatingagent-enhanced heavy metal extraction from a contaminated acidic soil. J. Environ. Eng., 130: 59-66. DOI: 10.1061/(ASCE)0733-9372(2004)130:1(59)

Luis, T.G., L.B. Rosario and B. Margarita, 2012. Removal of $\mathrm{As}, \mathrm{Cd}, \mathrm{Cu}, \mathrm{Ni}, \mathrm{Pb}$ and $\mathrm{Zn}$ from a highly contaminated industrial soil using surfactant enhanced soil washing. Phys. Chem. Earth, 37: 30-36. DOI: $10.1016 /$ j.pce.2011.02.003

Maturi, K. and K.R. Reddy, 2008. Extractants for the removal of mixed contaminants from soils. Soil Sediment Contaminat., 17: 586-608. DOI: $10.1080 / 15320380802425071$

Min, C., Z. Guangming, H. Danlian, Y. Chunping and L. Cui et al., 2017. Advantages and challenges of TWEEN 80 surfactant-enhanced technologies for the remediation of soils contaminated with hydrophobic organic compounds. Chem. Eng. J., 314: 98-113. DOI: 10.1016/J.CEJ.2016.12.135

Mulligan, C.N., R.N. Yong, B.F. Gibbs, S. James and H.P.J. Bennet, 1999. On the use of biosurfactants for the removal of heavy metals from oil-contaminated soil. Environ. Sci. Technol. J., 33: 3812-3820. DOI: $10.1021 / \mathrm{es} 9813055$

Metka, U. and L. Domen, 2009. Pb, Zn and Cd mobility, availability and fractionation in aged soil remediated by EDTA leaching. Chemosphere, 74: 1367-1373. DOI: 10.1016/j.chemosphere.2008.11.013 
Oudghiri, F., J.L. García-Morales and M.R. RodríguezBarroso, 2015. Evaluation of sediments decontamination by chelating agents using thermogravimetric analysis. Int. J. Environ. Res., 9: 657-662.

DOI: 10.1061/(ASCE)0733-9372(1997)123:3(217)

Pichtel, J. and T.M. Pichtel, 2009. Comparison of solvents for ex situ removal of chromium and lead from contaminated soil. Environ. Eng. Sci., 14: 97-104. DOI: 10.1089/ees.1997.14.97

Reddy, K.R. and C. Supraja, 2000. Comparison of extractants for removing heavy metals from contaminated clayey soils. Soil Sediment Contaminat., 9:449-462. DOI: 10.1080/10588330091134347

Salehian, E., A. Khodadadi and B. Hosseini, 2012. Remediation of diesel contaminated soils using surfactants: Coulumn study. Am. J. Environ. Sci., 8: 352-359. DOI: 10.3844/ajessp.2012.352.359

Sampanpanish, P. and T. Pojanaporn, 2014. Comparison of EDTA and EDDS enhancted phytoextraction of $\mathrm{Cr}$ and $\mathrm{Pb}$ from contaminated soil by Ananas comosus (1.) Merr. Am. J. Agric. Biol. Sci., 9: 361-368. DOI: 10.3844/ajabssp.2014.361.368

Semer, R. and K.R. Reddy, 1996. Evaluation of soil washing process to remove mixed contaminants from a sandy loam. J. Hazardous Mater., 45: 45-57. DOI: 10.1016/0304-3894(96)82887-1

Sun, B., F.J. Zhao, E. Lombi and S.P. McGrath, 2001. Leaching of heavy metals from contaminated soils using EDTA. Environ. Pollut., 113: 111-120. DOI: $10.1016 / \mathrm{S} 0269-7491(00) 00176-7$

Udovic, M. and D. Lestan, 2008. Pb, Zn and Cd mobility, availability and fractionation in aged soil remediated by EDTA leaching. Chemosphere, 74: 1367-1373. DOI: 10.1016/j.chemosphere.2008.11.013
USEPA, 1998. Microwave assisted acid digestion of aqueous samples and extracts. Method, 3051A, Washington D.C., USA.

USEPA, 1993. Innovation site remediation technology soil washing/soil flushing volume3. Office of Solid Waste and Emergency, Washington D.C., USA.

Villa, R.D., A.G. Trovo and N.R.F. Pupo, 2010. Soil remediation using a coupled process: Soil washing with surfactant followed by Photo-Fenton Oxidation. J. Hazardous Mater., 174: 770-775. DOI: 10.1016/j.jhazmat.2009.09.118

Zhang, W., D.C.W. Tsang and I.M.C. Lo, 2008. Removal of $\mathrm{Pb}$ by EDTA washing in the presence of hydrophobic organic contaminants or anionic surfactant. J. Hazardous Mater., 155: 433-439. DOI: 10.1016/j.jhazmat.2007.11.084

Zhang, W. and I.M.C. Lo, 2008. EDTA-enhanced washing for remediation of $\mathrm{Pb}$ - and/or Zn-contaminated soils. J. Environ. Eng., 132: 1282-1288. DOI: 10.1061/(ASCE)0733-9372(2006)132:10(1282)

Zou, Z., R. Qiu, W. Zhang, H. Dong and Z. Zhao et al., 2009. The study of operating variables in soil washing with EDTA. Environ. Pollut., 157: 229-236. DOI: 10.1016/j.envpol.2008.07.009

Yongyut, O., 2000. Phytonutrients. 1st Edn., Kasetsart University, Bangkok.

Xuhui, M., J. Rui, X. Wei and Y. Jiaguo, 2015. Use of surfactants for the remediation of contaminated soils: A review. J. Hazardous Mater., 285: 419-435. DOI: 10.1016/J.JHAZMAT.2014.12.009 